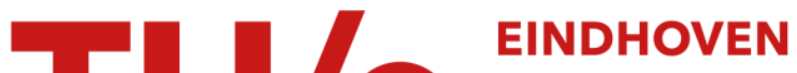 UNIVERSITY OF TECHNOLOGY
}

\section{Numerical modelling of hydraulic fracturing}

Citation for published version (APA):

Remij, E. W., Remmers, J. J. C., Huyghe, J. M. R. J., \& Smeulders, D. M. J. (2015). Numerical modelling of hydraulic fracturing. In F. Oka, A. Murakami, R. Uzuoka, \& S. Kimoto (Eds.), Computer Methods and Recent Advances in Geomechanics - Proceedings of the 14th Int. Conference of International Association for Computer Methods and Recent Advances in Geomechanics, IACMAG 2014 (pp. 1719-1723). Taylor \& Francis/ Balkema.

Document status and date:

Published: 01/01/2015

\section{Document Version:}

Accepted manuscript including changes made at the peer-review stage

\section{Please check the document version of this publication:}

- A submitted manuscript is the version of the article upon submission and before peer-review. There can be important differences between the submitted version and the official published version of record. People interested in the research are advised to contact the author for the final version of the publication, or visit the $\mathrm{DOI}$ to the publisher's website.

- The final author version and the galley proof are versions of the publication after peer review.

- The final published version features the final layout of the paper including the volume, issue and page numbers.

Link to publication

\section{General rights}

Copyright and moral rights for the publications made accessible in the public portal are retained by the authors and/or other copyright owners and it is a condition of accessing publications that users recognise and abide by the legal requirements associated with these rights.

- Users may download and print one copy of any publication from the public portal for the purpose of private study or research.

- You may not further distribute the material or use it for any profit-making activity or commercial gain

- You may freely distribute the URL identifying the publication in the public portal.

If the publication is distributed under the terms of Article 25fa of the Dutch Copyright Act, indicated by the "Taverne" license above, please follow below link for the End User Agreement:

www.tue.nl/taverne

Take down policy

If you believe that this document breaches copyright please contact us at:

openaccess@tue.nl

providing details and we will investigate your claim. 


\title{
Numerical modelling of hydraulic fracturing
}

\author{
E.W. Remij \& J.J.C. Remmers \& J.M. Huyghe \& D.M.J. Smeulders \\ Department of Mechanical Engineering \\ Eindhoven University of Technology, PO BOX 513, 5600 MB Eindhoven
}

\begin{abstract}
In this paper we present a numerical model for hydraulic fracturing purposes. The rock formation is modelled as a poroelastic material based on Biot's Theory. A fracture is represented in a discrete manner using the eXtended Finite Element Method (X-FEM). The fluid flow is governed by a local mass balance. This means that there is an equilibrium between the opening of the fracture, the tangential fluid flow, and the fluid leakage. The mass balance in the fracture is solved with a separate equation by including an additional degree of freedom for the pressure in the fracture. The fracture can grow in arbitrary directions by using an average stress criterion. We show a result of hydraulic fracture propagation for a $2 \mathrm{D}$ circular borehole. The fracture direction is consistent with the expected direction.
\end{abstract}

\section{INTRODUCTION}

Hydraulic fracturing is the process in which a fracture propagates by applying a high pressure inside the fracture. In geo-mechanics this process is used to stimulate oil and gas reservoirs by fracturing the underground rock formation. The induced fractures remain open, due to the addition of a proppant to the fracturing fluid, and therefore greatly enhance the permeability in the formation. Numerical models can be used to obtain more insight in the fracture process and may eventually be used to optimize the fracture process.

Boone \& Ingraffea (1990) developed a numerical model based on the finite element method (FEM) for the poroelastic material where a cohesive zone description was used for the fracture. Using a mesh adaptation scheme in a poroelastic FEM, Schreffler and co-workers (Schrefler et al. 2006, Secchi et al. 2007, Secchi and Schrefler 2012) simulated propagating hydraulic fractures in a arbitrary directions. Carrier \& Granet (2012) used a similar approach with a priori placed interface elements that contained an additional degree of freedom for the pressure in the fracture.
The eXtended Finite Element Method (X-FEM) was used by Mohammadnejad \& Khoei (2012) for cohesive crack growth in multiphase porous materials. They also successfully applied their model for hydraulic fracturing simulations (Mohammadnejad \& Khoei 2013).

$\mathrm{X}$-FEM is a common technique in solid mechanics and has as an important advantage compared to the previously mentioned fracture models; a fracture can grow in arbitrary directions without the need to remesh (Belytschko and Black 1999, Moës et al. 1999). By exploiting the partition of unity property of finite element shape functions (Melenk \& Babuška 1996), a fracture can be inserted in a finite element mesh by adding additional degrees of freedom to the nodes surrounding the fracture (Figure 1). In this contribution we present a similar X-FEM model as was used by Mohammadnejad \& Khoei (2013) but we also include the pressure in the fracture as a separate degree of freedom. Such a formulation ensures that all the pumping fluid goes into the fracture. The new model is refereed to as the Enhanced Local Pressure (ELP) model. 


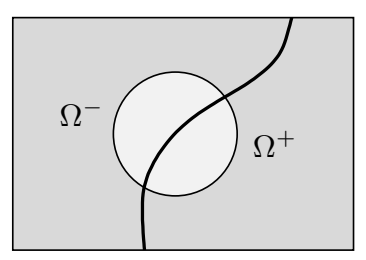

- Enhanced node ○ Regular node

Figure 1: A two dimensional finite element mesh crossed by a fracture represented by the black line. The black nodes surrounding the fracture are enhanced with additional degrees of freedom. The grey elements therefore contain additional terms in the stiffness matrix and the force vector.

\section{KINEMATIC RELATIONS}

The total displacement field of the solid skeleton can, at any time $t$, be described by a continuous displacement field $\hat{\mathbf{u}}(\mathbf{x}, t)$ and a discontinuous displacement field $\tilde{\mathbf{u}}(\mathbf{x}, t)$ (Belytschko \& Black 1999, Moës, Dolbow, \& Belytschko 1999)

$\mathbf{u}(\mathbf{x}, t)=\hat{\mathbf{u}}(\mathbf{x}, t)+\mathcal{H}_{\Gamma_{\mathrm{d}}}(\mathbf{x}) \tilde{\mathbf{u}}(\mathbf{x}, t)$,

We can also write the pressure field as a sum of the continuous field $\hat{p}(\mathbf{x}, t)$ and a discontinuous field $\tilde{p}(\mathbf{x}, t)$.

$p(\mathbf{x}, t)=\hat{p}(\mathbf{x}, t)+\mathcal{H}_{\Gamma_{\mathrm{d}}}^{\mathrm{s}}(\mathbf{x}) \tilde{p}(\mathbf{x}, t)$.

The functions $\mathcal{H}_{\Gamma_{\mathrm{d}}}$ and $\mathcal{H}_{\Gamma_{\mathrm{d}}}^{\mathrm{s}}$ are Heaviside step functions defined over the fracture as

$\mathcal{H}_{\Gamma_{\mathrm{d}}}=\left\{\begin{array}{lll}1 & \text { if } & \mathbf{x} \in \Omega^{+} \\ 0 & \text { if } \quad \mathbf{x} \in \Omega^{-}\end{array}\right.$

$\mathcal{H}_{\Gamma_{\mathrm{d}}}^{\mathrm{s}}=\left\{\begin{array}{lll}\frac{1}{2} & \text { if } & \mathbf{x} \in \Omega^{+} \\ -\frac{1}{2} & \text { if } & \mathbf{x} \in \Omega^{-} .\end{array}\right.$

With these formulations the pressure inside the fracture is undetermined. We therefore introduce a third pressure $p_{d}$, representing the pressure in the fracture. The continuous fields are present in all the finite element nodes. The discontinuous fields and the pressure in the fracture are only included in the enhanced nodes (Figure 1).
The pressure in the fracture is a one dimensional variable that can be used to describe the fluid mass balance in the fracture. Integrating the local mass balance gives

$$
\begin{array}{r}
\mathbf{q}_{\Gamma_{\mathrm{d}}}^{+} \cdot \mathbf{n}_{\mathrm{d}}-\mathbf{q}_{\Gamma_{\mathrm{d}}}^{-} \cdot \mathbf{n}_{\mathrm{d}}+[\dot{\mathbf{u}}]_{n}+u_{n}\left\langle\frac{\delta \dot{u}_{s}}{\delta s}\right\rangle- \\
u_{n} \frac{\delta}{\delta s}\left(k_{\mathrm{d}} \frac{\delta p_{\mathrm{d}}}{\delta s}\right)+\frac{u_{n}}{M_{f}} \dot{p_{\mathrm{d}}}=0
\end{array}
$$

with $\mathbf{q}_{\Gamma_{\mathrm{d}}}^{+}$and $\mathbf{q}_{\Gamma_{\mathrm{d}}}^{-}$being the fluid flow from the fracture into formation for the fracture side of the $\Omega^{+}$and the $\Omega^{-}$domain, respectively, $[\dot{\mathbf{u}}]_{n}$ denoting the time derivative of the normal opening of the fracture, $u_{s}$ being the shear opening of the fracture, and $k_{\mathrm{d}}$ being the permeability in the fracture. Assuming a Couette flow, the latter is given by

$k_{\mathrm{d}}=\frac{u_{n}^{2}}{12 \mu}$,

where $\mu$ is the viscosity of the fluid, and $u_{n}$ the opening of the fracture. The derivation of this equation can be found in Irzal et al. (2013).

Using the cohesive zone approach, the damaging of the material is described by a traction acting on the fracture. This traction is coupled to the hydrostatic pressure in the crack. Assuming continuity of stress from the formation to the fracture, we can write the local momentum balance as

$\boldsymbol{\sigma} \cdot \mathbf{n}_{\mathrm{d}}=\mathbf{t}_{\mathrm{d}}-p_{\mathrm{d}} \mathbf{n}_{\mathrm{d}}$

\section{NUMERICAL FORMULATION}

The time discretization is performed with an implicit Euler scheme. The non-linear system of equations is finally solved by using a Newton-Raphson iterative procedure. We consider the porous material to be fully saturated with a fluid and subjected to small variations in the displacement gradient. The bulk poroelasticity is based on Biot theory.

The propagation time and the propagation direction of the fracture are based on an average stress criterion. The stress values surrounding the tip of the cohesive zone are weighted with a Gaussian function (Jirásek 1998). The average stress is then the weighted sum of stresses in these integration points. 


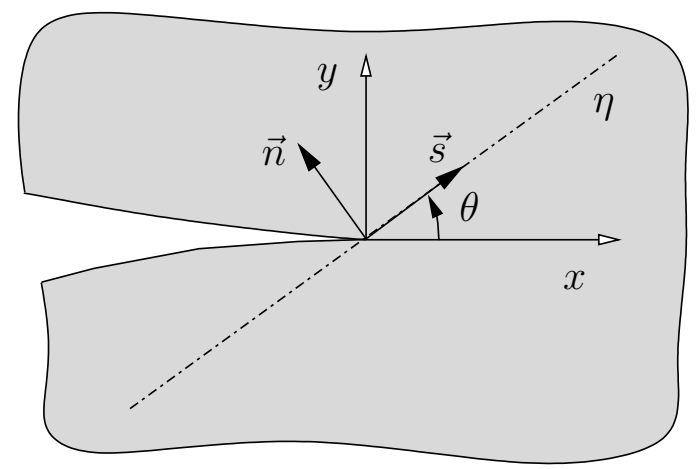

Figure 2: Schematic representation of a material with at the crack tip the global $x-y$ coordinate system and the local coordinate system, described with a normal unit vector $\mathbf{n}$ and a tangential unit vector $\mathbf{s}$.

$\boldsymbol{\sigma}_{\mathrm{av}}=\sum_{i=1}^{\mathrm{n}_{\mathrm{int}}} \frac{w_{i}}{w_{\mathrm{tot}}} \boldsymbol{\sigma}_{\mathrm{e}, i} \quad$ with $\quad w_{\mathrm{tot}}=\sum_{j=1}^{\mathrm{n}_{\text {int }}} w_{j}$.

Here $n_{\text {int }}$ is the number of integration points in the domain, $\boldsymbol{\sigma}_{\mathrm{e}, i}$ is the current effective stress state in integration point $i$ which has a weight factor $w_{i}$ defined as

$w_{i}=\frac{(2 \pi)^{\frac{2}{3}}}{l_{\mathrm{a}}^{3}} e^{\frac{-r_{i}^{2}}{2 l_{a}^{2}}}$,

with $r_{i}$ being the distance between the tip of the cohesive zone and the integration point $n_{i}$, and $l_{\mathrm{a}}$ being a length scale parameter defining how fast the weight factor decays as a function of the distance between the integration points and the cohesive zone tip. Based on the average stress, an equivalent traction is calculated (Camacho \& Ortiz 1996)

$t_{\mathrm{eq}}(\theta)=\sqrt{<t_{n}>^{2}+\frac{1}{\beta} t_{s}^{2}}$,

with

$<t_{n}>=\left\{\begin{array}{ll}0 & \text { if } \quad t_{n} \leq 0 \\ t_{n} & \text { if } \quad t_{n}>0\end{array}\right.$,

where $t_{n}$ and $t_{s}$ respectively are the normal and shear traction

$t_{n}=\mathbf{n}^{T} \boldsymbol{\sigma}_{\mathrm{av}} \mathbf{n} \quad t_{s}=\mathbf{s}^{T} \boldsymbol{\sigma}_{\mathrm{av}} \mathbf{n}$.
Here $\mathbf{n}$ is the normal vector and $\mathbf{s}$ is the tangent vector to an axis $\eta$ which is rotated by an angle $\theta$ with respect to the $\mathrm{x}$-axis (Figure 2 ). If the maximum equivalent traction exceeds the yield strength $\tau_{\text {ult }}$ of the material the fracture is extended in the direction of angle $\theta$ through one element. The fracture is assumed to open as a cleavage crack. The traction separation relation is given by (Camacho \& Ortiz 1996)

$t_{n}=t_{n_{0}}\left(1-\frac{v_{n}}{v_{n_{c r}}}\right)$

$t_{s}=t_{s_{0}}\left(1-\frac{v_{n}}{v_{n_{c r}}}\right) \operatorname{sgn}\left(\mathrm{v}_{\mathrm{s}}\right)$.

Here $v_{n}$ and $v_{s}$ are respectively the normal and sliding the displacement, $\operatorname{sgn}(\cdot)$ is the Signum function. The parameter $v_{n_{c r}}$ is the length of the fully developed traction-free crack. This parameter depends on the fracture toughness $\mathcal{G}_{c}$ and the initial normal traction $t_{n_{0}}$

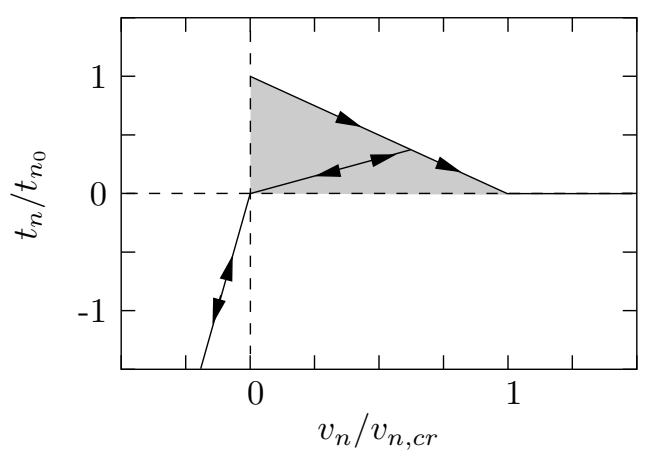

Figure 3: The normalized tractions across the fracture as a function of the displacement jump in.

$v_{n_{c r}}=\frac{2 \mathcal{G}_{c}}{t_{n_{0}}}$.

The initial tractions, $t_{n_{0}}$ and $t_{s_{0}}$, are taken equal to the normal and shear tractions at the time of propagation, respectively. Self-contact of the fracture is simulated by using a penalty stiffness method. A detailed description of the numerical implementation can be found in the work (Remmers, de Borst, \& Needleman 2008) and the usage of X-FEM in porous materials is given in (Kraaijeveld \& Huyghe 2011, Réthoré, Borst, \& Abellan 2007). 


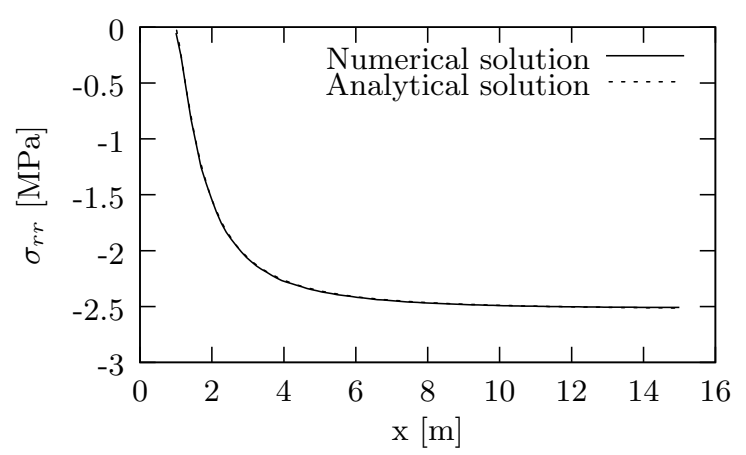

(a) Radial stress

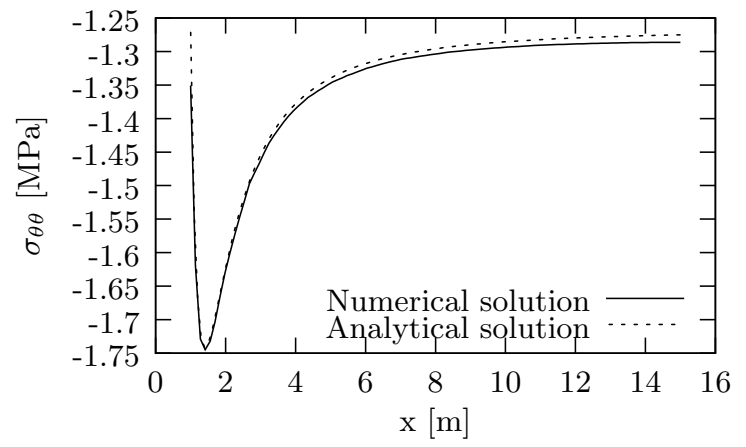

(b) Circumferential stress

Figure 4: The results of the numerical solution and analytical solution for the Kirsch problem plotted over the $\mathrm{x}$-axis.

\section{EXAMPLES}

The performance of the numerical model is addressed by considering a 2D borehole problem (Figure 5). The rock formation is assumed to be a squared specimen with a dimension of $10.0 \mathrm{~m}$. The circular hole has a radius of $1.0 \mathrm{~m}$. The confining stress is taken as $\sigma_{0}=5.0[\mathrm{Mpa}]$ in y-direction, and is taken twice as large in the x-direction. The material parameters are given in Table 1.

Applying the confining stress leads to consolidation effects in the bulk material due to a poroelastic response. In order to obtain an initial equilibrated state we perform one time step with a prescribed zero pressure in all the nodes. After this first step we release the pressure, place the initial fractures and start the fluid inflow $q_{0}$.

The initial stress field is compared with Kirsch analytical solution for a circular hole in an infinite elastic solid (Kirsch 1898). The radial stress and the circular stress over the $\mathrm{x}$-axis are shown in Figure 4.

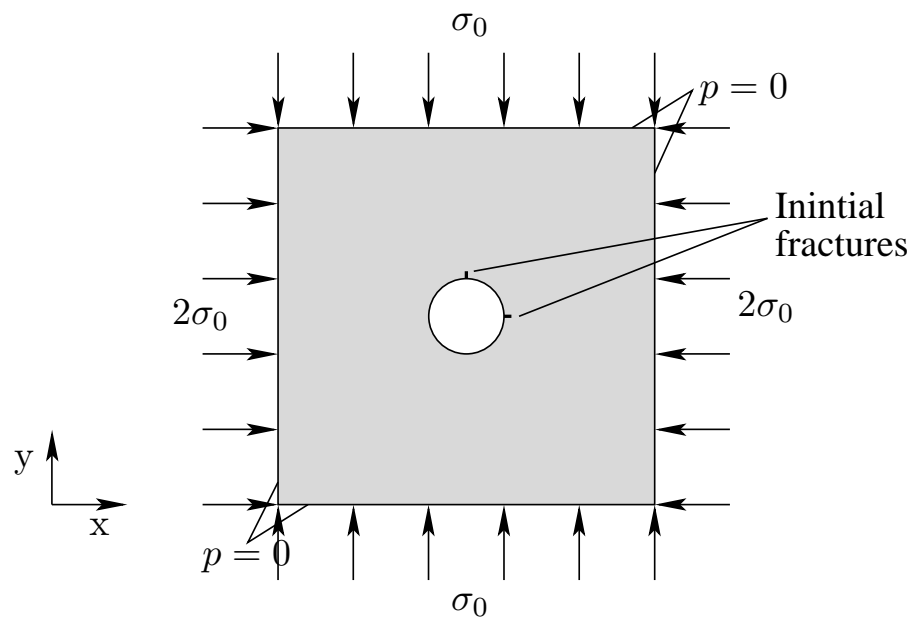

Figure 5: Scheme of the borehole fracture problem.

Table 1: Model Parameters used in the borehole fracture problem.

\begin{tabular}{lll}
\hline Name & Symbol & Value \\
\hline Young's modulus & $E$ & $17.0 \mathrm{GPa}$ \\
Poisson's ratio & $\nu$ & 0.2 \\
Ultimate strength & $\tau_{\text {ult }}$ & $1.25 \mathrm{MPa}$ \\
Fracture toughness & $\mathcal{G}_{c}$ & $120.0 \mathrm{Nm}^{-1}$ \\
Fluid viscosity & $\mu$ & $1.0 e^{-4} \mathrm{~Pa} \cdot \mathrm{s}$ \\
Fluid injection rate & $q_{0}$ & $0.05 \mathrm{~ms}^{-1}$ \\
Bulk modulus solid & $K_{\mathrm{s}}$ & $36.0 \mathrm{GPa}$ \\
Bulk modulus fluid & $K_{\mathrm{f}}$ & $3.0 \mathrm{GPa}$ \\
Biot coefficient & $\alpha$ & 0.75 \\
\hline
\end{tabular}

The preferred propagation direction of a hydraulic fracture is perpendicular to the minimum confining stress (Hubbert \& David 1972). In order to investigate if the numerical model can predict this behaviour we also perform the simulation with only the initial fracture in the y-direction. The time evolution of this fracture is shown in Figure 6a. If we consider both initial fractures, indeed only the fracture that is perpendicular to the minimum confining stress propagates, as shown in Figure 6b.

\section{CONCLUSIONS}

The performance of the ELP model is addressed in a $2 \mathrm{D}$ circular borehole problem. In the first case only the initial fracture perpendicular to the highest confining stress is included in the simulation. This is the unfavourable direction of fracture propagation. 

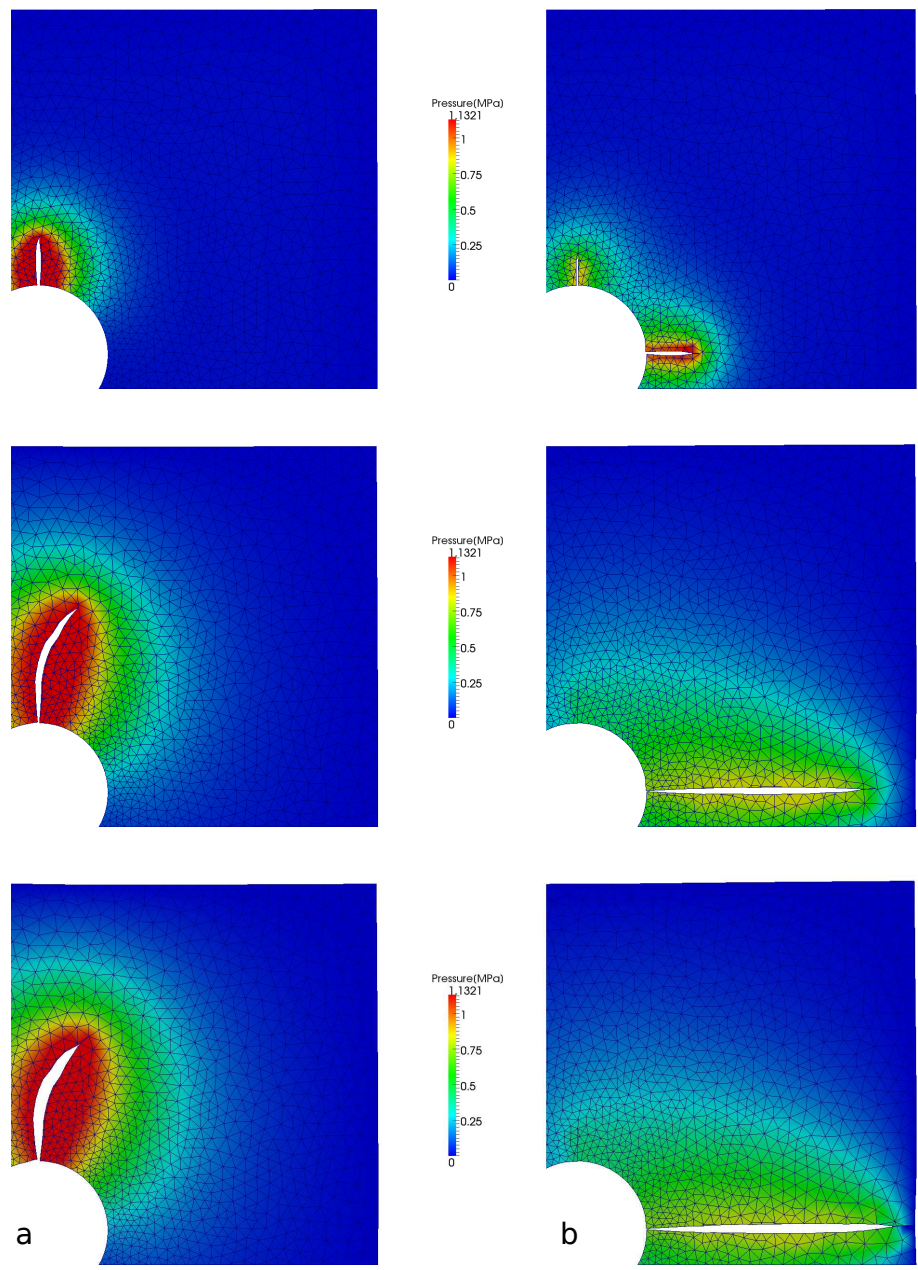

Figure 6: Contour plots of the hydrostatic pressure for the borehole problem at 3 different times. The deformed mesh is magnified 100 times. (a) A propagating fracture turns in the direction of the minimum confining stress. (b) Only the fracture perpendicular to the minimum confining stress propagates. The second fracture in the y-direction is not visible because it is closed.

The propagated fracture indeed turns in the direction of the highest confining stress. In the second case also the fracture that is already in the direction of the highest confining stress is included. Now only the second fracture grows while the fracture that is initially perpendicular to the highest confining stress remains closed. This behaviour is consistent with findings in the literature (Hubbert \& David 1972).

\section{ACKNOWLEDGEMENT}

This research project is supported by the Dutch TKI Gas Foundation.

\section{REFERENCES}

Belytschko, T. \& T. Black (1999). Elastic crack growth in finite elements with minimal remeshing. International journal for numerical methods in engineering 45(5), 601-620.

Boone, T. \& A. Ingraffea (1990). A numerical procedure for simulation of hydraulically-driven fracture propagation in poroelastic media. International Journal for $\mathrm{Nu}$ merical and Analytical Methods in Geomechanics 14(1), $27-47$.

Camacho, G. \& M. Ortiz (1996). Computational modelling of impact damage in brittle materials. International Journal of solids and structures 33(20), 2899-2938.

Carrier, B. \& S. Granet (2012). Numerical modeling of hydraulic fracture problem in permeable medium using cohesive zone model. Engineering Fracture Mechanics 79, $312-328$.

Hubbert, M. \& G. W. David (1972). Mechanics of hydraulic fracturing. US Geological Survey 210, 153-168.

Irzal, F., J. Remmers, J. Huyghe, \& R. de Borst (2013). A large deformation formulation for fluid flow in a progressively fracturing porous material. Computer Methods in Applied Mechanics and Engineering, 29-37.

Jirásek, M. (1998). Embedded crack models for concrete fracture. In Computational Modelling of Concrete Structures, EURO C-98, Volume 1, pp. 291-300.

Kirsch, G. (1898). Die Theorie der Elastizität und die Bedürfnisse der Festigkeitslehre. Zeitschrift des Vereines deutscher Ingenieure 42, 797-807.

Kraaijeveld, F. \& J. Huyghe (2011). Propagating cracks in saturated ionized porous media. Multiscale Methods in Computational Mechanics, 425-442.

Melenk, J. \& I. Babuška (1996). The partition of unity finite element method: basic theory and applications. Computer methods in applied mechanics and engineering 139(1), 289-314.

Moës, N., J. Dolbow, \& T. Belytschko (1999). A finite element method for crack growth without remeshing. International journal for numerical methods in engineering 46(1), 131-150.

Mohammadnejad, T. \& A. Khoei (2012). Hydro-mechanical modeling of cohesive crack propagation in multiphase porous media using the extended finite element method. International Journal for Numerical and Analytical Methods in Geomechanics 37(10), 1247-1279.

Mohammadnejad, T. \& A. Khoei (2013). An extended finite element method for hydraulic fracture propagation in deformable porous media with the cohesive crack model. Finite Elements in Analysis and Design 73, 77-95.

Remmers, J., R. de Borst, \& A. Needleman (2008). The simulation of dynamic crack propagation using the cohesive segments method. Journal of the Mechanics and Physics of Solids 56(1), 70-92.

Réthoré, J., R. Borst, \& M. Abellan (2007). A two-scale approach for fluid flow in fractured porous media. International Journal for Numerical Methods in Engineering 71(7), 780-800.

Schrefler, B., S. Secchi, \& L. Simoni (2006). On adaptive refinement techniques in multi-field problems including cohesive fracture. Computer methods in applied mechanics and engineering 195(4), 444-461.

Secchi, S., L. Simoni, \& B. Schrefler (2007). Mesh adaptation and transfer schemes for discrete fracture propagation in porous materials. International Journal for $\mathrm{Nu}$ merical and Analytical Methods in Geomechanics 31(2), 331-345.

Secchi, S. \& B. Schrefler (2012). A method for 3D hydraulic fracturing simulation. International journal of fracture $178(1-2), 245-258$. 